\title{
Streptococcus iniae sp. nov., a Beta-Hemolytic Streptococcus Isolated from an Amazon Freshwater Dolphin, Inia geoffrensis
}

\author{
GERALD B. PIER ${ }^{1}$ AND STEWART H. MADIN \\ Department of Biomedical and Environmental Health Sciences, School of Public Health, University of \\ California Berkeley, California 94720; and Steinhart Aquarium, California Academy of Science, Golden \\ Gate Park, San Francisco, California 94122
}

\begin{abstract}
Evidence is presented for the recognition of a new species of Streptococcus isolated from abscess foci in an Amazon freshwater dolphin, Inia geoffrensis. The organism appears to be immunologically distinct from members of the recognized Lancefield groups of streptococci. Antigens prepared by five different extraction procedures do not react with antisera to Streptococcus groups $\mathrm{A}$ to $\mathrm{U}$, whereas antisera prepared against the new isolate react well with the extracted homologous antigens but not with antigens from groups A to U. Based on cultural, morphological, biochemical, and serological results, it is suggested that this isolate belongs to a new species for which we propose the name Streptococcus iniae. The type strain of this new species is strain PW (=ATCC 29178).
\end{abstract}

The basis for the serological grouping of betahemolytic streptococci, as originally defined by Lancefield (11), rests on the demonstration of a distinct immunological specificity of an antiserum to the group-specific " $\mathrm{C}$ " polysaccharide usually located in the cell wall (10). Currently there are 19 recognized serogroups, each presumably having a different chemical composition or structure of the "C" polysaccharide (19). The serogroups often indicate the host specificity of the organism; for example, group A streptococci are primarily associated with human disease, group B streptococci are mostly associated with bovine mastitis (12), and group $\mathrm{E}$ streptococci are mostly associated with swine infections $(1,20)$. This paper describes a betahemolytic streptococcus isolated from an Amazon freshwater dolphin, Inia geoffrensis, suffering from an acute infection termed "golf ball disease."

In March 1972, oné of us (S.H.M.) was asked to examine a freshwater dolphin reportedly suffering from golf ball disease. On inspection, the animal, a mature adult male, was found to have numerous subcutaneous abscess foci on both sides of the thoracic and abdominal cavities. These abscess foci were discrete, rounded masses, 2 to $5 \mathrm{~cm}$ in diameter, which were raised approximately 1 to $2 \mathrm{~cm}$ above the skin surface and which fluctuated upon palpation. There were approximately 25 such foci on the right side of the animal and about 15 on the left.

1 Present address: Department of Bacterial Diseases, Walter Reed Army Institute of Research, Washington, D.C. 20012.
When excised, these foci were shown to contain 2 to $5 \mathrm{ml}$ of purulent exudate which, when cultured, contained few or no organisms. However, when cultures were obtained by swabs from the interior surface of the abscess wall and streaked onto blood agar, a pure culture of a beta-hemolytic streptococcus grew in abundance.

This original culture was sensitive to penicillin, and treatment was instituted using a mixture of long-acting penicillin and tylocin. After intensive treatment for 10 days, the animal made an uneventful recovery.

The disease, known as golf ball disease because of the resemblance of the foci to golf balls, is believed by aquarists to be fatal for this particular species, as was the case with two specimens of $I$. geoffrensis that had contracted the disease at The Steinhart Aquarium in San Francisco, Calif. A brief review of the disease and its pathology will be reported elsewhere.

In studying the streptococcus isolated from the skin lesion, we were unable to obtain a grouping reaction with any serum against the recognized serogroups utilizing antigen prepared by the Lancefield hot $\mathrm{HCl}$ method (11), the Fuller formamide method (5), the Rantz and Randall hot autoclave method (17), the Streptomyces albus lytic enzyme method (16), or extraction with Pronase (4). The chance that the dolphin had contracted the disease from one of its handlers or from another aquarium animal was considered, so we examined the possibility of its being a member or a variant of either group A or group C. However, the isolate 
was resistant to the action of a group $C$ bacteriophage and its phage-associated murilysin, which lyses group A streptococci (19). Our serological and biochemical findings were confirmed by R. R. Facklam, Center for Disease Control (CDC), Atlanta, Ga., and R. L. Wood, National Animal Disease Center (NADC), Ames, Iowa. Further studies also indicated that the organism is a member of a previously undescribed species of Streptococcus. The following evidence is presented for regarding this isolate as belonging to a new species of Streptococcus.

\section{MATERIALS AND METHODS}

Bacterial strains. In addition to the new organism, the isolation of which was described above, three other streptococcal strains were employed for comparison of characteristics and for testing with the phage murilysin. Group A strain C203 and group C strain Azgazarhad were provided by J. T. Douglas from our department. Another group $\mathrm{C}$ streptococcus, one isolated from a guinea pig suffering from chronic streptococcal lymphadenitis, was provided by A. Larson, also of our department.

Maintenance and growth of cultures. The dolphin skin lesion was lanced, and a swab from the interior wall of the lesion was streaked onto blood agar base plates containing 5\% sheep red blood cells (Microbiological Associates) for colony differentiation and hemolysis testing. Single colonies of a pure culture of a beta-hemolytic streptococcus were then transferred to Todd-Hewitt broth (THB) and incubated overnight at $37^{\circ} \mathrm{C}$. For stock cultures, brain heart infusion agar (BHIA) slants were inoculated and similarly incubated. New subcultures were made every 2 months. The other three strains were maintained on BHIA slants in a similar manner. For the preparation of material for vaccines, antigens, deoxyribonucleic acid (DNA) isolation, murilysin testing, and staining, the organisms were grown overnight in THB at $37^{\circ} \mathrm{C}$.

Morphological studies. Blood agar plates (BAP) were used to study colonial morphology and cellular appearance on solid media. Todd-Hewitt broth was used to study growth in broth and cellular appearance in liquid media. Incubation of the above was at $37^{\circ} \mathrm{C}$ overnight.

Physiological studies. The inoculum for physiological studies was prepared by picking single colonies from a blood agar plate into $3 \mathrm{ml}$ of THB, incubating for $3 \mathrm{~h}$ until there was slight visible turbidity, and then pipetting $0.1 \mathrm{ml}$ into the test media.

Acid production from carbohydrates was determined in phenol red broth base, supplemented with $1 \%$ (wt/vol) of the appropriate sugar. The following carbohydrates were used: arabinose, dextran, dulcitol, fructose, galactose, glucose, glycerol, inositol, inulin, lactose, maltose, mannitol, mannose, melibiose, raffinose, rhamnose, salicin, sorbitol, sucrose, trehalose, and xylose. Tubes were examined for 5 days, and acid production was determined by com- parison of the color produced in the inoculated culture with that of an uninoculated control tube similarly incubated. Catalase production was determined on BHIA plates.

Sodium hippurate hydrolysis, gelatin hydrolysis, starch hydrolysis, growth in 6.5, 4.0, and $2.5 \%$ $\mathrm{NaCl}$, growth in 10 and $40 \%$ bile, and growth in $0.04 \%$ tellurite, $0.1 \%$ tetrazolium, and bile-esculin media were measured by adding the appropriate test substance to THB. Reaction in litmus milk was determined from stock media, and the methylene blue milk reaction was determined by the addition of the dye to skim milk. Esculin agar medium was prepared by the method of Shuman et al. (18). All reactions were observed for 5 days. Nitrate reduction was first tested for by R. R. Facklam, CDC, Atlanta, Ga., and then confirmed by ourselves.

Antibiotic susceptibility test. The qualitative antibiotic test was performed by the standardized method of Kirby and Bauer (21) on Mueller-Hinton plates (Baltimore Biological Laboratories [BBL]) containing $5 \%$ defibrinated sheep blood. Susceptibility disks (BBL) were placed on the agar by a dispenser, and plates were incubated overnight at $37^{\circ} \mathrm{C}$. Zones of inhibition were then measured and susceptibilities were determined.

DNA base composition. Organisms grown overnight were harvested for isolation of their DNA by the method of Marmur (13), with the following modifications: $2.5 \mathrm{~g}$ (wet weight) of cells was suspended in $5 \mathrm{ml}$ of saline-ethylenediaminetetraacetic acid (EDTA) and added to $5 \mathrm{~g}$ of fine glass beads (Minnesota Mining and Manufacturing). The mixture was shaken in a Mickle cell disintegrator for $2 \mathrm{~h}$ at $4^{\circ} \mathrm{C}$. The entire mixture was diluted to $25 \mathrm{ml}$ with salineEDTA, $2 \mathrm{ml}$ of sodium dodecyl sulfate was added, and incubation was carried out for $10 \mathrm{~min}$ at $60^{\circ} \mathrm{C}$. The procedure then followed the Marmur method, with the glass beads being removed in the first centrifugation.

The melting temperature $\left(T_{m}\right)$ of the DNA was determined by the method of Marmur and Doty (14), and the moles percent guanine plus cytosine ( $\mathrm{mol} \%$ $\mathrm{G}+\mathrm{C}$ ) was calculated by the method of DeLey (2).

Serological study. Antigens for testing the groupspecific polysaccharide were prepared by the following methods: (i) Lancefield hot $\mathrm{HCl}$ (11), (ii) Fuller hot formamide (5), (iii) Rantz and Randall hot autoclave (17), (iv) Streptomyces albus enzyme (16) using commercially prepared Lytase (BBL), and (v) Pronase $\mathrm{B}$ (Calbiochem) extraction at $50^{\circ} \mathrm{C}$ for $2 \mathrm{~h}(4)$.

Antiserum was produced in New Zealand White rabbits, weighing about $2 \mathrm{~kg}$ each, by repeated intravenous (i.v.) injections of either a formalinkilled preparation of the organism or a saline suspension of an overnight culture of the live organism. Both preparations were adjusted to approximately $10^{7}$ colony-forming units (CFU) per ml with the aid of a Klett-Summerson colorimeter. A 50-ml volume of blood was removed from each rabbit by cardiac puncture, and the serum was collected. Subsequent booster inoculations and bleedings were done on a monthly basis.

Both capillary and small-tube ring precipitin tests were used to assay the sera and antigens. The 
ring test gave very quick results and was, therefore, most often used. Gel diffusion was carried out in agarose gel (Sigma Biochemicals) prepared in veronal buffer by a method supplied by $R$. L. Wood, NADC, Ames, Iowa.

Commercial antisera for testing were obtained from Difco Laboratories and from Baltimore Biological Laboratories, and commercial antigens were from Difco Laboratories.

Tests for confirmation of nonmembership of dolphin isolate in group $A$ or group $C$. For each of the strains studied, $1 \mathrm{ml}$ of a log-phase culture was added to $9 \mathrm{ml}$ of THB at $37^{\circ} \mathrm{C}$ and incubated for $4 \mathrm{~h}$. A $1-\mathrm{ml}$ volume of the lysate of a group $\mathrm{C}$ bacteriophage and the Azgazarhad strain of Streptococcus group C, previously prepared and tested for sterility and murilytic enzyme activity against Streptococcus group A, was then added, and the growth or lysis was followed by periodic measurements in a KlettSummerson colorimeter. Group A, group C, and variants of these two groups would be lysed by this preparation.

Animal studies. Outbred guinea pigs, both males and females weighing between 350 and $900 \mathrm{~g}$, were inoculated with the organism, either subcutaneously (s.c.), intraperitoneally (i.p.), or intracardially (i.c.), to test for susceptibility. Pen-bred, closedcolony NAMRU 1 mice (6) from the Naval Biosciences Research Laboratory, Oakland, Calif., were inoculated i.p. and s.c. to test for susceptibility to the dolphin isolate. As stated earlier, rabbits were inoculated i.v. with the live organism to test for susceptibility and also to produce antisera.

Corroboration of new serogroup status of dolphin isolate. A live culture, prepared antisera, and a hot-autoclave antigen preparation of the dolphin isolate were submitted to $R$. R. Facklam, CDC Atlanta, Ga., and to R. L. Wood, NADC, Ames, Iowa, in order to compare the serological properties of the dolphin isolate to those of members of previously described serogroups of Streptococcus.

\section{RESULTS}

Morphology. The organism (strain PW) isolated from a freshwater dolphin is characterized as follows: gram-positive, encapsulated cocci, up to $1.5 \mu \mathrm{m}$ in diameter, most often occurring in long chains in broth culture (Fig. 1).

On solid blood agar media, a small (up to 1 $\mathrm{mm}$ in diameter), white, umbonate colony with an entire opaque border, an opaque center spot, and a translucent ring of growth separating the border and the center was produced. The colony was surrounded by a small to moderate area of beta hemolysis, beyond which was a diffuse outer ring of alpha hemolysis (Fig. 2).

The growth in broth was very characteristic of the dolphin isolate, yielding a coarse, white,

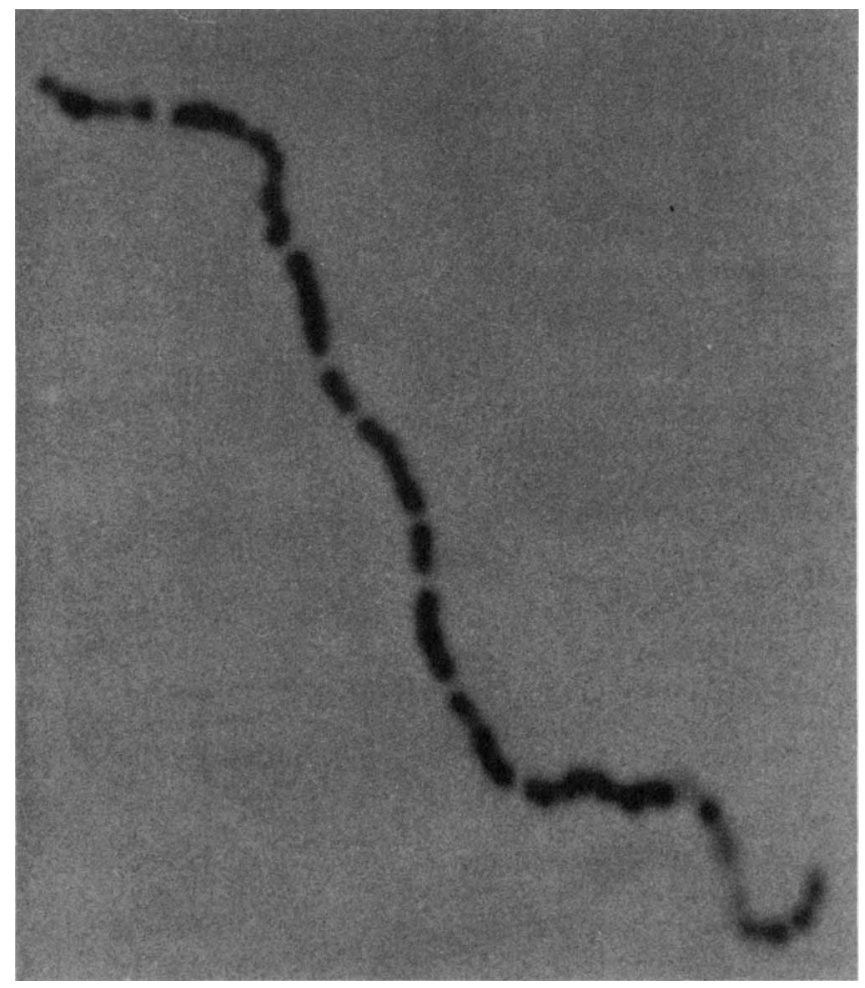

FIg. 1. Gram stain of dolphin isolate. Magnification, $\times 1,200$. 


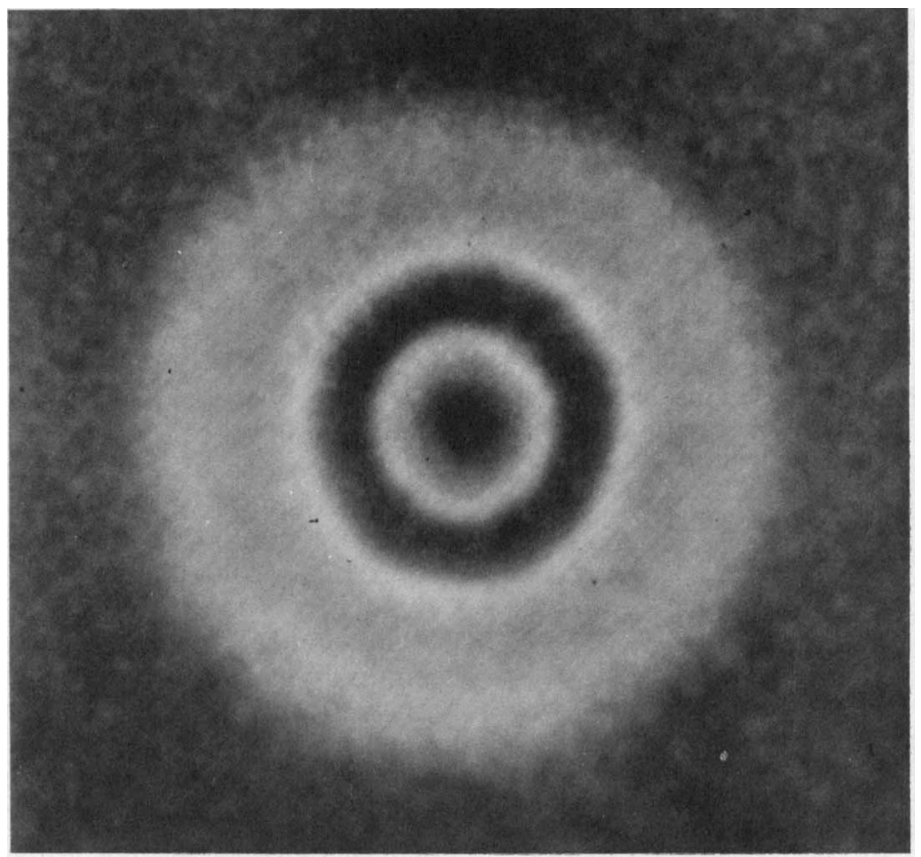

FIG. 2. Blood agar colony of dolphin isolate. Magnification, $\times 40$.

granular material that grew mostly at the bottom of the tube, leaving the top three-quarters speckled with a granular growth that readily fell to the bottom of the tube when disturbed, especially in tubes with smaller volumes (Fig. $3)$. obic.

The organism is aerobic, facultatively anaer-

Fermentation studies. Acid is produced from dextran, fructose, galactose, glucose, maltose, mannitol, mannose, salicin, sucrose, and trehalose. No change in $\mathrm{pH}$ occurs in arabinose, dulcitol, glycerol, inositol, inulin, lactose, melibiose, raffinose, rhamnose, sorbitol, or xylose.

Biochemical characteristics. Significant biochemical reactions in selected test media commonly used to characterize streptococci are shown in Table 1.

Antibiotic susceptibility. Table 2 shows the antibiotic susceptibility spectrum of the organism. The susceptibility pattern is very close to that demonstrated by Matsen and Coghlan (15) for groups A, C, and G streptococci, especially in regard to the aminoglycoside antibiotics. Thus, it is susceptible to gentamicin but resistant to kanamycin, neomycin, and streptomycin. Furthermore, the organism is susceptible to a 2-unit disk of bacitracin, but not to the 0.05 unit disk used to differentiate group A from non-group A streptococci.

DNA base composition. On the basis of three separate determinations, an average $T_{m}$ of
TABLE 1. Biochemical reactions of the dolphin isolate (strain PW)

\begin{tabular}{lc}
\hline \multicolumn{1}{c}{ Test } & Reaction $^{a}$ \\
\hline Production of catalase & - \\
Reduction of nitrate & $-{ }^{b}$ \\
Growth in/at: & - \\
Bile-esculin media & + \\
Methylene blue milk, $0.005 \%$ & - \\
Methylene blue milk, $0.1 \%$ & - \\
$6.5 \%$ NaCl & + \\
$4.0 \% \mathrm{NaCl}$ & + \\
$2.0 \%$ NaCl & - \\
$10 \%$ Bile broth & - \\
$40 \%$ Bile broth & - \\
$0.04 \%$ Tellurite & + \\
$0.1 \%$ Tetrazolium & + \\
$10^{\circ} \mathrm{C}$ & - \\
$45^{\circ} \mathrm{C}$ & \\
Hydrolysis of: & + \\
Starch & - \\
Sodium hippurate & - \\
Gelatin & + \\
Esculin &
\end{tabular}

$a+$, Positive test or growth; - , negative test or no growth.

${ }^{b}$ Test performed by R. R. Facklam, CDC, Atlanta, Ga.

$82.9^{\circ} \mathrm{C}$ (range 82.8 to 82.9 ) for the DNA in $1 \times$ standard saline citrate was found. This gave a calculated value of $32.9 \mathrm{~mol} \% \mathrm{G}+\mathrm{C}$, which is close to the values reported for other strepto- 


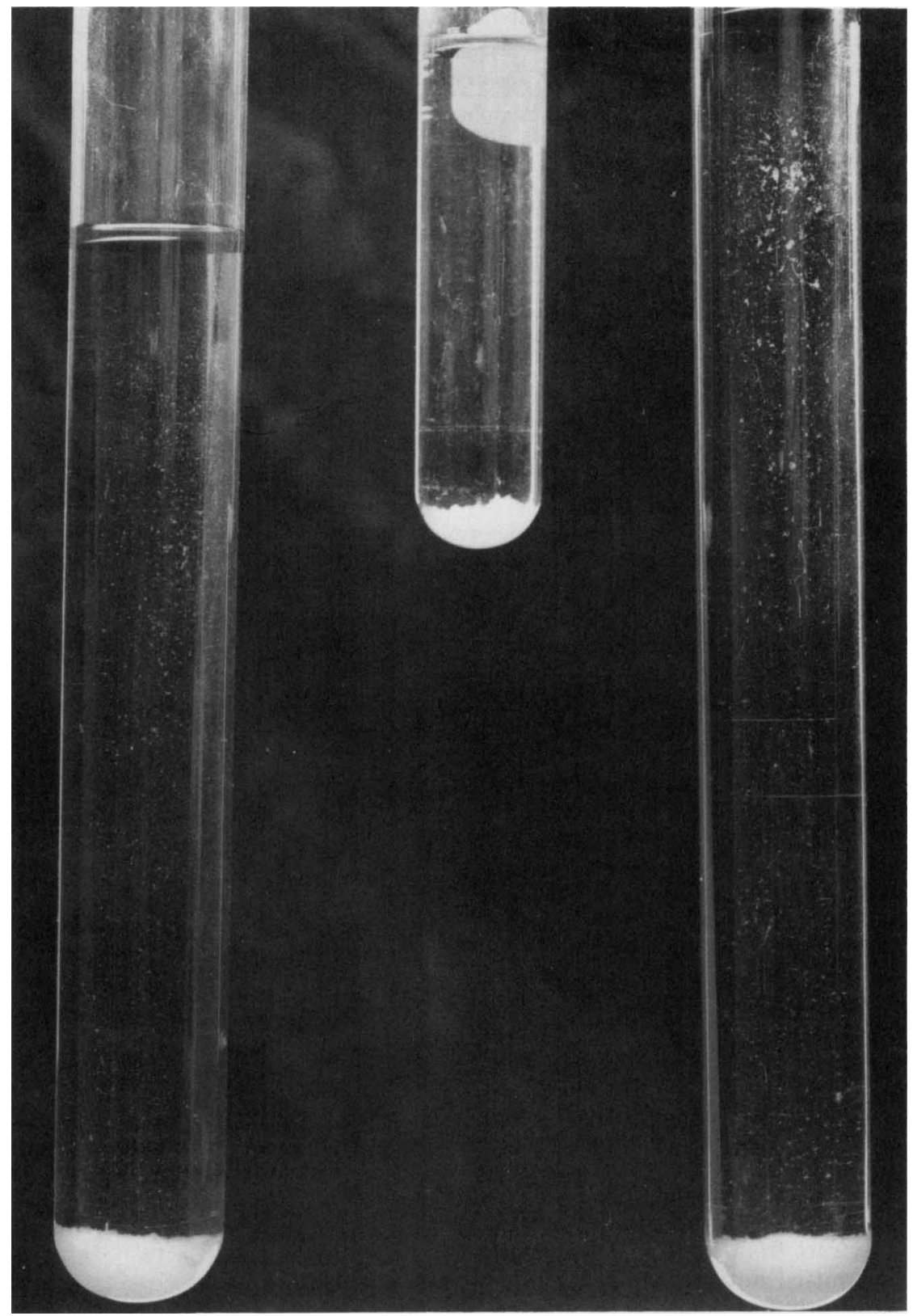

Fig. 3. Growth in broth of dolphin isolate. Note increase in granules in tubes with larger volumes. Volume of left-hand tube is $40 \mathrm{ml}$, center tube is $10 \mathrm{ml}$, and right-hand tube is $60 \mathrm{ml}$.

cocci (8) but slightly lower than the lowest value reported $(33.6 \mathrm{~mol} \% \mathrm{G}+\mathrm{C})$ for them.

Confirmation of nonmembership of dolphin isolate in group A or group C. Since preliminary testing of the dolphin isolate did not yield a grouping reaction with antisera available to us, we then tried testing the sensitivity of the dolphin isolate to a group $\mathrm{C}$ bacteriophage and its associated murilysin to see if we had a group A, group C, or a variant strain of one of these two groups. When the organism was subjected to $1 \mathrm{ml}$ of the lysate of strain Azgazarhad of group $\mathrm{C}$, the culture proceeded to grow to stationary phase. A different 1-ml sample of the same lysate, when added to a growing culture of strain C203 of group A, reduced the turbidity 
TABLE 2. Antibiotic susceptibilities of the dolpin isolate (strain PW) ${ }^{a}$

\begin{tabular}{lll}
\multicolumn{1}{c}{ Resistant to: } & \multicolumn{1}{c}{$\begin{array}{c}\text { Intermediate } \\
\text { susceptibility to: }\end{array}$} \\
\hline Gantrisin $(300 \mu \mathrm{g})^{b}$ & Chloramphenicol $(30 \mu \mathrm{g})$ & Susceptible to: \\
Kanamycin $(30 \mu \mathrm{g})$ & & Ampicillin $(2 \mu \mathrm{g})^{c}$ \\
Nalidixic acid $(5 \mu \mathrm{g})$ & & Bacitracin $(2 \mathrm{units})$ \\
Neomycin $(30 \mu \mathrm{g})$ & & Carbenicillin $(50 \mu \mathrm{g})$ \\
Polymixin B $(300 \mathrm{U})$ & & Cephalothin $(30 \mu \mathrm{g})$ \\
Streptomycin $(10 \mu \mathrm{g})$ & & Cephaloridine $(30 \mu \mathrm{g})$ \\
Sulfadimethoxine $(50 \mu \mathrm{g})^{d}$ & Cloxacillin $(1 \mu \mathrm{g})$ \\
Sulfisomidine $(50 \mu \mathrm{g})$ & Erythromycin $(5 \mu \mathrm{g})$ \\
& & Gentamicin $(10 \mu \mathrm{g})$ \\
& & Lincomycin $(2 \mu \mathrm{g})$ \\
& & Methcillin $(5 \mu \mathrm{g})$ \\
& & Nafcillin $(1 \mu \mathrm{g})$ \\
& & Nitrofurantoin $(50 \mu \mathrm{g})$ \\
& & Oleandomycin $(2 \mu \mathrm{g})$ \\
& & Penicillin $(2 \mathrm{U})$ \\
& & Oxytetracycline $(5 \mu \mathrm{g})$ \\
\hline
\end{tabular}

a Standard Kirby-Bauer method.

${ }^{b}$ Resistant and intermediate susceptibilities determined by potency of highest disk dose employed in test.

c Lowest disk dose employed in test.

${ }^{d}$ Sulfa drugs tested on Mueller-Hinton agar plates without added sheep blood.

to near zero within $20 \mathrm{~min}$. Another $1-\mathrm{ml}$ sample, however, reduced the turbidity of a growing culture of a group $\mathrm{C}$ streptococcus isolated from a guinea pig to near zero within $35 \mathrm{~min}$. The dolphin isolate was, therefore, not affected by the phage-associated murilysin, as are the group A streptococci, and did not possess receptor sites or allow phage multiplication, as do group $\mathrm{C}$ strains (9).

Confirmation of serological uniqueness. Commercial streptococcal antisera tested against the five extracts prepared from the dolphin isolate failed to yield a precipitin reaction, whereas antisera prepared by us against both a formalized vaccine and live culture reacted well with these extract preparations. Furthermore, our antisera did not react with commercially prepared antigens of streptococcal groups A through $\mathrm{T}$. However, due to the variability of commercial preparations, we submitted the materials mentioned above to CDC and NADC. R. R. Facklam at CDC prepared and tested a Lancefield extract from the live culture along with our submitted antigen against available grouping antisera for Lancefield's groups A through $\mathbf{U}$ and four proposed new groups and found no reaction. Lancefield extracts of groups A through $U$ and the four proposed groups did not react with our antisera, whereas the homologous serum and the CDC-prepared and our submitted antigen reacted specifically. $R$. L. Wood at NADC performed a similar series of tests using a Fuller formamide extract from the live culture. He could not obtain a reaction with our serum to extracts of groups A through $U$ or to 12 other "nongroupable" streptococci, nor did antisera to these groups elicit a reaction with

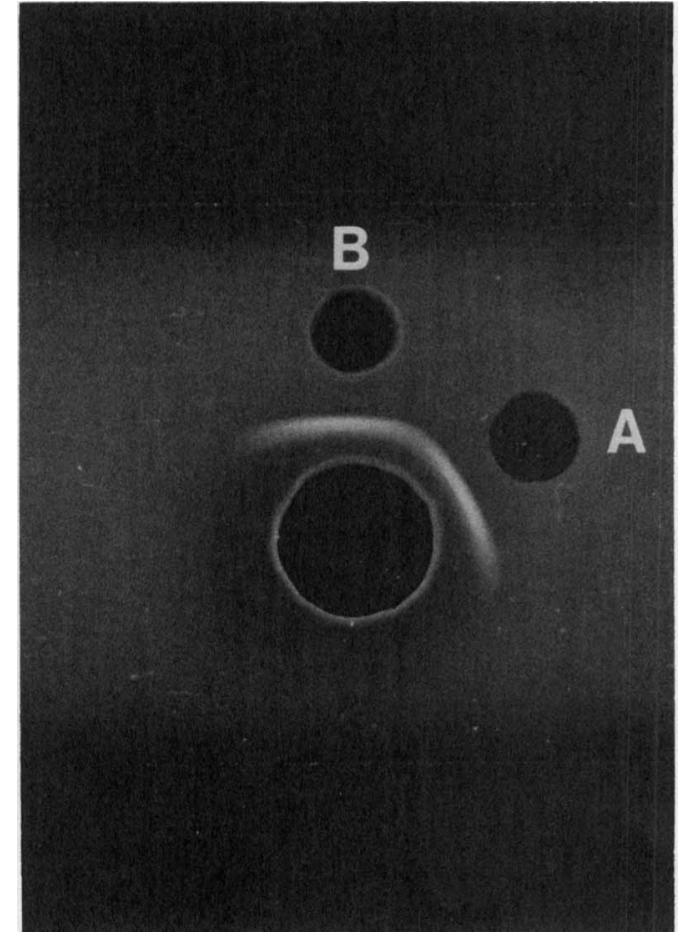

Fig. 4. Gel diffusion of reaction of identity between NADC-prepared Fuller formamide extract (A) and our prepared Rantz and Randall extract (B) with our antisera. Test and photograph courtesy of National Animal Disease Center, U.S. Department of Agriculture.

either the submitted antigen or the prepared antigen. However, a reaction of identity was observed in an Ouchterloney double-diffusion system between the NADC-prepared antigen 
and our submitted Rantz and Randall extract when tested against our antiserum (Fig. 4). Our own tests showed a reaction of identity between antigens prepared by the $\mathrm{HCl}$ method, formamide method, autoclave method, and Streptomyces albus lytic enzyme method (Fig. 5).

Animal studies. Guinea pigs were found to be resistant to challenge with up to $10^{8} \mathrm{CFU}$ of the dolphin isolate by either the s.c., i.p., or i.c. route in terms of any visible disease syndrome or distress. Mice were resistant to i.p. and s.c. challenge of up to $10^{7} \mathrm{CFU}$, whereas rabbits were negative after initial i.v. injections of $10^{8}$ live CFU. Thus, we could produce no noticeable disease in any of these three species of laboratory animals.

\section{DISCUSSION}

Beta-hemolytic streptococci seem to occur widely throughout the animal world as pathogenic agents. Many different animal species

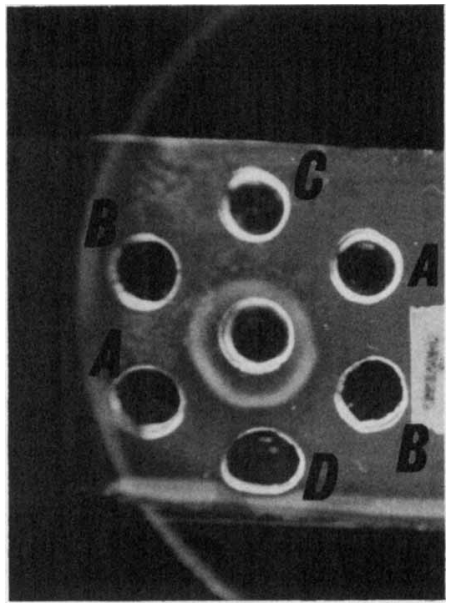

FIG. 5. Reaction of identity between four different antigen-isolation procedures and antisera. (A) Lancefield hot $\mathrm{HCl}$, (B) Fuller formamide, (C) Rantz and Randall autoclave, (D) Streptomyces albus lytic enzyme extract.

TABLE 3. Comparison of characteristics of dolphin isolate (strain PW) with Streptococcus infrequens (Lancefield groups $E, P$, and $U$ ) and Streptococcus uberis ${ }^{a}$

\begin{tabular}{|c|c|c|c|c|c|}
\hline \multirow{2}{*}{ Characteristic } & \multirow{2}{*}{$\begin{array}{l}\text { Dolphin } \\
\text { isolate }\end{array}$} & \multicolumn{3}{|c|}{ S. infrequens } & \multirow{2}{*}{ S. uberis } \\
\hline & & $\underset{\mathrm{E}}{\text { Group }}$ & $\underset{P}{\text { Group }}$ & $\underset{\mathrm{U}}{\text { Group }}$ & \\
\hline \multicolumn{6}{|l|}{ Acid from: } \\
\hline Arabinose & $-b$ & - & $+1-$ & $+1-$ & - \\
\hline Dextran & + & + & + & + & + \\
\hline Dulcitol & - & - & - & - & - \\
\hline Fructose & + & + & + & + & + \\
\hline Galactose & + & + & + & + & + \\
\hline Glucose & + & + & + & + & + \\
\hline Glycerol & - & $+1-$ & $+1-$ & + & - \\
\hline Inositol & - & - & - & - & - \\
\hline Inulin & - & - & - & - & + \\
\hline Lactose & - & $+1-$ & $+1-$ & $+1-$ & + \\
\hline Mannitol & + & + & + & + & + \\
\hline Mannose & + & + & + & + & + \\
\hline Raffinose & - & - & - & - & - \\
\hline Rhamnose & - & - & - & - & - \\
\hline Salicin & + & + & + & + & + \\
\hline Sorbitol & - & + & + & + & + \\
\hline Sucrose & + & + & + & + & + \\
\hline Trehalose & + & + & + & + & + \\
\hline \multicolumn{6}{|l|}{ Growth in/at: } \\
\hline Litmus milk & $\mathrm{SA}^{c}$ & SA/A & $\mathrm{SA} / \mathrm{A}$ & A & A \\
\hline $\begin{array}{l}\text { Methylene blue } \\
\text { milk, } 0.1 \%\end{array}$ & - & $+1-$ & + & + & - \\
\hline $\mathrm{NaCl}, 6.5 \%$ & - & $+1-$ & + & + & + \\
\hline Bile, $40 \%$ & - & - & $+1-$ & - & - \\
\hline $10^{\circ} \mathrm{C}$ & + & $+1-$ & $+1-$ & + & + \\
\hline $45^{\circ} \mathrm{C}$ & - & - & - & - & - \\
\hline \multicolumn{6}{|l|}{ Hydrolysis of: } \\
\hline Sodium hippurate & - & - & - & - & + \\
\hline Esculin & + & + & + & + & + \\
\hline
\end{tabular}

${ }^{a}$ Data from Shuman et al. (18).

${ }^{\circ}+$, Positive reaction;,- , negative reaction; $+/-$, variable reaction, strain or colony-pick dependent.

" A, Acid produced; SA, slight acid produced. 
suffer from various kinds of streptococcal infections, with a particular serogroup of streptococci often associated with a specific host. Therefore, it is not unusual to find a previously unidentified species of Streptococcus associated with a disease syndrome in a rarely studied animal.

Due to the enormous expense of obtaining and housing specimens of $I$. geoffrensis, it is difficult to apply Koch's postulates (7) to proving the etiology of golf ball disease. Furthermore, the exhibition value of these animals to aquaria prohibits obtaining blood from the dolphin. Consequently, a test for antibodies to the isolated streptococcus could not be made. However, because of the lesion from which we obtained the original culture, the recovery made by the animal on antibiotic therapy, and the apparent uniqueness of the isolated streptococcus, we feel reasonably certain that this organism either is the etiologic agent of golf ball disease or is intimately associated with the disease as an opportunistic agent.

An interesting biochemical relationship of the dolphin isolate to groups $\mathrm{E}, \mathrm{P}$, and $\mathrm{U}$ streptococci (Streptococcus infrequens) and Streptococcus uberis can be seen from Table 3 . The dolphin isolate differs from $S$. infrequens strains only by its lack of fermentation of sorbitol. It differs from S. uberis by its lack of fermentation of sorbitol and inulin and its inability to hydrolyze sodium hippurate.

DeMoor and Thal (3) found two group $\mathrm{E}$ and one group $P$ strain that did not ferment sorbitol; these strains also did not ferment sucrose, mannitol, or salicin, which are fermented by the dolphin isolate. Although it is common to find nongroupable streptococci in animals, the fact that R. L. Wood at NADC could find no serological reaction with extracts of the dolphin isolate and antisera to 12 nongroupable strains adds more weight to the uniqueness of this organism. The closely related biochemical properties of the dolphin isolate and $S$. infrequens will be of interest to the current problem of classification of groups $\mathrm{E}, \mathrm{P}$, and $\mathrm{U}$ streptococci and $S$. uberis $(3,18)$. The structural and chemical composition of the $\mathrm{C}$ polysaccharide is currently under investigation.

The morphology and the DNA composition of the dolphin isolate establish the organism as a member of the genus Streptococcus. The serological and biochemical data support the recognition of this isolate as a new species of Streptococcus. It would be appropriate that, after consideration by the Taxonomic Subcommittee on Streptococci and Pneumococci of the International Committee on Systematic Bacteriology, this organism be designated with a Lancefield grouping letter to indicate its unique and distinct relationship to the currently recognized serogroups of streptococci. We further propose that this new species be named Streptococcus iniae. The type strain is strain PW; a culture of this strain has been deposited in the American Type Culture Collection under the accession number 29178. Because the present description of $S$. iniae is based on a single strain, the description of this species is also the description of the type strain. Obviously, strain PW is only a member of this species, and the description of $S$. iniae will be modified as additional strains of this species are isolated and characterized.

\section{ACKNOWLEDGMENTS}

We thank Leon Hunter of the Naval Biosciences Research Laboratory, Oakland, Calif., for his assistance in measuring the melting temperature of the isolated DNA. We wish to thank the late Earl S. Herald and Robert Dempster of The Steinhart Aquarium, California Academy of Sciences, Golden Gate Park, San Francisco, Calif., for their permission to treat the animal and for their subsequent cooperation.

The work described in this manuscript was supported in part by Public Health Service Grant \#5 T01 A100332-05 of the National Institute of Allergy and Infectious Diseases, The National Institutes of Health, and by a faculty research grant from the Committee on Research, University of Califormia.

\section{REPRINT REQUESTS}

Address reprint requests to: Dr. Gerald B. Pier, Department of Bacterial Diseases, Walter Reed Army Institute of Research, Washington, D.C. 20012.

\section{LITERATURE CITED}

1. Armstrong, C. H., and J. B. Payne. 1969. Bacteria recovered from swine affected with cervical lymphadenitis. Am. J. Vet. Res. 30:1607-1612.

2. DeLey, J. 1970. Reexamination of the association between melting point, buoyant density and chemical composition of deoxyribonucleic acid. J. Bacteriol. 101:738-754.

3. DeMoor, C. E., and E. Thal. 1968. Beta-hemolytic Streptococci of the Lancefield groups E, P, and U Streptococcus infrequens. Antonie van Leeuwenhoek J. Microbiol. Serol. 34:377-387.

4. Ederer, G. M., M. M. Herrmann, R. Bruce, J. M. Matsen, and S. S. Chapman. 1972. Rapid extraction method with Pronase B for grouping beta-hemolytic Streptococci. Appl. Microbiol. 23:285-288.

5. Fuller, A. T. 1938. The formamide method for the extraction of polysaccharides from hemolytic streptococci. Br. J. Exp. Pathol. 19:130-138.

6. Garber, E. D., and F. C. Hauth. 1950. A new mutation with asymmetrical expression in the mouse. J. Herd. 41:122-124.

7. Koch, R. 1881. Zur züchtung von pathogenen Mikroorganismen, Mitt. Kaiserlichen Gesundheitsamte 1:148.

8. Kocur, M., T. Bergan, and N. Mortensen. 1971. DNA base composition of gram positive cocci. J. Gen. Microbiol. 69:167-183.

9. Krause, R. M. 1958. Studies of bacteriophages of hemolytic streptococci, II. Antigens released from the streptococcal cell wall by a phage associated lysin. J. Exp. Med. 108:803-821. 
10. Krause, R. M. 1972. The streptococcal cell: relationship of structure to function and pathogenesis, p. 4-18. In L. W. Wannamaker and J. M. Matsen (ed.), Streptococci and streptococcal diseases. Academic Press Inc. New York.

11. Lancefield, R. C. 1933. A serological differentiation of human and other groups of hemolytic streptococci. J. Exp. Med. 57:571-595.

12. Lancefield, R. C. 1934. A serological differentiation of specific types of bovine hemolytic streptococci (Group B). J. Exp. Med. 59:441-458.

13. Marmur, J. 1961. A procedure for the isolation of deoxyribonucleic acid from microorganisms. J. Mol. Biol. 3:208-218.

14. Marmur, J., and P. Doty. 1962. Determination of the base composition of deoxyribonucleic acid from its thermal denaturation temperature. J. Mol. Biol. 5:109-118.

15. Matsen, J. M., and C. R. Coghlan. 1972. Antibiotic testing and susceptibility patterns of streptococci, p.
189-204. In L. W. Wannamaker and J. M. Matsen (ed.), Streptococci and streptococcal diseases. Academic Press Inc., New York.

16. Maxted, W. R. 1948. Preparation of streptococcal extracts for Lancefield grouping. Lancet 2:255-256.

17. Rantz, L. A., and E. Randall. 1955. Use of autoclaved extracts of hemolytic streptococci for serological grouping. Stanford Med. Bull. 13:290-291.

18. Shuman, R. D., N. Nord, R. W. Brown, and G. E. Wéssman. 1972. Biochemical and serological characteristics of Lancefield groups E, P, and U streptococci and Streptococcus uberis. Cornell Vet. 62:540-568.

19. Slade, H. D., and W. C. Slamp. 1962. Cell wall composition and the grouping antigens of streptococci. J. Bacteriol. 84:345-357.

20. Snoeyenbos, H. J., B. A. Bachman, and E. J. Wilson. 1952. Abscesses associated with Group E streptococci. J. Am. Vet. Med. Assoc. 120:134-137.

21. Standard Disc Susceptibility Test. 1972. Federal Register 37(no. 191):20527. 